\title{
The Roles of TQM and JIT for Basic Metal Industries Global Competitiveness
}

\author{
Dametew AW ${ }^{1,2 *}$, Kitaw $D^{1}$ and Ebinger $O^{2}$ \\ ${ }^{1}$ Addis Ababa Institute of Technology, Addis Ababa University, Ethiopia \\ ${ }^{2}$ Technische Hochschule Nürnberg Georg Simon Ohm, Germany
}

\begin{abstract}
The purpose of this study is to develop an integrated continuous improvement model so as to improving the global competitiveness of basic metal industries. The study concerned on the Ethiopian basic metal-manufacturing firms, with a special emphasis on the medium and large manufacturing industries. However, basic metal industries occupy a prominent position in the development agenda of many developing countries like Ethiopia. Hence, this study investigated the role of continuous improvement for global competition of basic metal industries, so as to tackle global competition problems on the firms. From numerous contentious improvements, we have to emphasis integrated JIT and TQM implementation on basic metal industries to improve competitive performance. The survey study is conduct through field observation, literature review of research articles, books, magazines, manuals, company report and electronic-sources which are analysis. A case study also conducted at Kaliti Metal Products Factory. The survey data is analyzed using descriptive analysis, SPCT (fishbone diagram). At literature level, the global competitiveness of Ethiopian economy was assessed and the current trends of continuous improvement tools implementation for global competitiveness of basic metal industries was analyzed. Poor supply chain system, manpower, raw material problems, energy fluctuation, outdated technology, manufacturing systems, financial and logistics problems are identified as the obstacles and influence the Ethiopian basic metal industry performance and global competitiveness. Based on the investigations an integrated continuous improving models are developed so as to improve the performance and global competitiveness of basic metal industries.
\end{abstract}

Keywords: Basic metal industries; Integrating model development continuous improvement; TIT and TQM; Global Competitiveness; Ethiopia

\section{Introduction and Background}

\section{Introduction}

Companies are expected to think of local as well as international competition in order to be competitive or even continue to exist. In today's' global competition environment, continuous improvement programs are considered to be a crucial tool to industries for improving and optimize their performance. This leads to improve the production and manufacturing processes of organizations, enhancing the efficiency and effectives of their systems, reduce costs and improved cycle times. However, continuous improvement is a philosophy and a system that provides to organizational improvements for their successes and reduces failures. These continual improvement processes requires the ability to understand the processes that affect the objectives of the organization, to measure process effectiveness, efficiency; firm performance and global competitiveness. Global competition has caused fundamental changes in the competitive environment of manufacturing industries. However, sustainable economic development is regularly measured by the competitiveness of the company at global, regional and national level. As a result countries are now keen on promoting their competitiveness in global market as it brings investments and more market opportunities [1]. Also indicates that Companies are expected to think of local as well as international competition in order to be competitive. Meanwhile the image of countries, in relation to their legal framework, and the supporting policies, reflects their eagerness to increase the opportunity of to compete globally. In addition A nation's ability to compete in the global marketplace has a direct bearing on the quality of life of its citizens. Because the ability to compete translates into the ability to do a better job of producing quality goods, it is critical that nations and individual organizations within them focus their policies, systems, and resources in a coordinated way on continually improving both quality and competitiveness.

For now, in industrial world, basic metal and engineering industry is regarded as the backbone for industrial development. Since the growth of basic metal and engineering industry is the key to social and economic advancement.

\section{Background}

The Ethiopia Basic Metal and Engineering Industries (BMEIs) are identified as one of the eight priority sub-sectors for medium and large industries development in the Growth and Transformation Plan (GTP). In particular, the BMEIs are considered as the primary industries to contribute to import substitution-based industrial development, which is newly emphasized in the GTP (JiCA 2010). However, Ethiopian basic metal industries deal with production of metal from ore, scrap and conversion of billet, slabs etc. into primary metal products such as, tubes bars, hot rolled ribbed and plain reinforcement bars, wire rod, angles, cold rolled tubes of various profiles, cold rolled sheets, galvanized sheets and tubes. The primary metal products produced by basic metal industries are subsequently raw materials (inputs) for the downstream engineering industries. Hence, basic metal industries is backward connected to mining sector and forward to all engineering industries and railway, constructions,

*Corresponding author: Dametew AW, Addis Ababa Institute of Technology, Addis Ababa University, Ethiopia, Tel: +251913032751; E-mail: alie20123@gmail.com

Received March 26, 2017; Accepted April 25, 2017; Published April 30, 2017

Citation: Dametew AW, Kitaw D, Ebinger O (2017) The Roles of TQM and JIT for Basic Metal Industries Global Competitiveness. Ind Eng Manage 6: 212 doi:10.4172/2169-0316.1000212

Copyright: ( 2017 Dametew AW, et al. This is an open-access article distributed under the terms of the Creative Commons Attribution License, which permits unrestricted use, distribution, and reproduction in any medium, provided the original author and source are credited. 
the expansion of electricity networking sector. Basic Metal industries through engineering industries also, industries forward linked to all sub-sectors of manufacturing industries. It can help; agricultural, construction, transports and electric power sectors, by manufacturing agricultural implements, manufacturing of production machinery construction machinery and structural bars and sections, vehicles, electrical equipment, respectively. On the other hand the sustainability of metallurgical industries also depends on the technology selected, the availability of resources, infrastructure, knowledge and production facilities. Hence, the development of basic metal industry is essential to the rapid growth of all other industries and country growth. That's why industrial economies are characterize by the survival of strong metal manufacturing industries. Because metal industry pay vital role for human civilization, modern technology, technological innovations, development of any modern economy. Since technological innovations and strong economy have provided the competitive edge to companies and increasingly competitive pressure on the firms to be technologically superior to others.

\section{Statement of the problems}

Ethiopia basic metal industry is infant for GTP economic contribution and global competition. At the same time most of Ethiopian basic metal manufacturing industries has limited and improper improvement system. the pervious study [2-4] shows that Ethiopian basic metal industry, is characterized by lowest level of industrialization and poor performance, poor production capacity, poor innovation, problems product quality, poor export capacity. As a result, in the Ethiopia basic metal industries has not yet made their share of markets and their GDP contribution still low [3,5]. Consequently, this research is designed to study the role of continuous improvement programs for global competiveness of basic metal industry and attempted to fill this gap. Hence, the main of the study is to develop an integrated continuous improvement model so as to improving firm performance and the global competitiveness of basic metal industries.

\section{Research methodology}

The study is conduct through field observation, literature review of research articles, books, magazines, manuals, company report and electronic-sources which are discuss related to basic metal manufacturing industries growth, opportunities, economic contribution, challenges, strengths and performances in relation to continuous improvement (TQM and JIT). The analysis consider attempts to investigate continuous quality improvement issue on basic metal industry, performance, competitiveness strategy, quality challenges in Ethiopia basic metal industry, and then a case study is conduct on Kality Metal product company for continuous improvement effort is assessed. Finally the conclusion and recommendation of the study is done (Figure 1).

\section{Literature Review}

\section{Global competitiveness}

Competitiveness is widely considered to be a major determinant of a country's relative economic performance and remains a core theme of the strategy argue. However today, with the rise of the digital economy and the advent of network business world, the competition between companies is fierce and more complex. In order to respond to a fast-changing business environment, companies began to pursue a strategy of innovation from a long-term perspective, rather than the conventional management paradigm such as short-term profit maximization. According to Kitaw [6] competitiveness can be conceptualized at different level including: at macro-economic level and firm or company level. At the macro-economy level, competitiveness is identified with a steady upward trend measured by GDP growth, productivity of resources and factors of production growing in macro-terms, and economic expansion onto the international market (enlargement of existing markets as well as entry into new market), that is, with the capacity of offering new, better and cheaper goods and services in a competitive environment. On the other hand at individual firms' level, competitiveness is the ability of a firm to survive and prosper, given the competition of other firms for the same profits. The competitiveness of a firm is the result of a comparative advantage relative to other firms. Other scholars [7] also defined as for example Samsung Electronics not only has accelerated the development of new

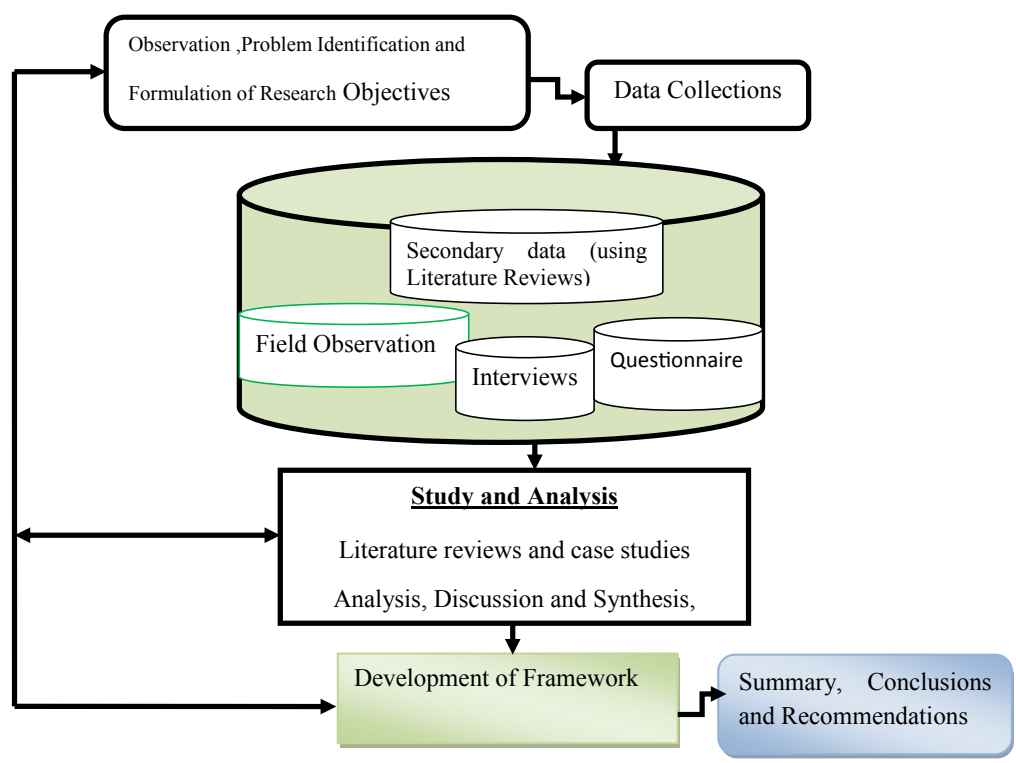

Figure 1: Research Methodology Frame work. 
products, it has reinforced the competitiveness of its overall ecosystem through technology and management advice to subcontractors.

In addition [8] global competitiveness, report defines competitiveness as the set of institutions, policies, and factors that determine the level of productivity of a country. In addition ref. [9] describe as the ability to maintain a steady growth rate of real per capita income, measured by pace of growth in gross domestic product (GDP) per capita at constant prices.

Despite this, competitiveness is not a concept which can easily be applied and is difficult to measure, as the factors which are thought to underpin it are numerous and highly inter-related. As a result competitive manufacturing industry provides in which companies improve their performance by increasing productivity through managerial and technological development, changes, innovations, and offer better quality or lower-priced goods and services, thereby expanding demand for their products. So, the concept of global competitiveness has therefore emerged to enhance the mutual benefits of organizations. Since integration of manufacturing firms with new technology and new management systems are the key for the success and competitiveness of organizations.

From this competitiveness have comprehensive system or way the ability to produce better than other firms the right goods or services of right quality, at the right price and the right time. It means meeting customer's needs more effectively and more efficiently equivalently or more than other firms. Addition competitiveness is also measure in terms of sustainability the product to the market by achieving customer expectations. Thus to assess Ethiopia basic metal industries global competitiveness, it is easy to measure the extent to which it is coping positively in the global game-play and enhances competitiveness a diagnostic analysis of a subsisting relationship and encourages a prescription of policies to achieve better firm performance.

\section{The Pillars and the drivers of manufacturing industry competitiveness}

The resource efficiency, the new investments in education and skills, machinery and equipment, physical and technological infrastructure and innovation (including commercialization) will all contribute to improvementsin productivity, competitiveness and success. Manufacturing industries relies on three fundamental pillars: factors, standards and costs are viewed within a comparative framework; these three pillars define the competitiveness of firm or a nation. However the competitiveness of any organization in the world is measured and evaluated with the prospective of quality driving elements shown in Table 1.

Since, from the prospective point of these pillars the competitiveness of basic metal industries can be determined.

\section{Continuous improvement (Continuous improvement tools and techniques)}

Organizations can have improvement choices with time depending up on the way they track to meet their strategic and operational objectives. Science continuous improvement raises the competence of numerous processes and systems and is closely integrated with means of waste elimination and there by customer focus programs such as total quality management, just-in-time and kaizen.

Just-in-time (JIT): JIT is a systematic approach to achieve competitiveness and excellence in manufacturing industries by eliminate sources of manufacturing waste for getting right quantity of raw materials and producing the right quantity of products in the right place at the right time. Scholars $[10,11]$ show that JIT is as a powerful tool for continuous manufacturing improvement based on the elimination of wastes in all phases of manufacturing process. According to these studies, JIT highly affects financial, time and flexibility performances of manufacturing companies. As result due to its effectiveness in reducing production costs, improving product quality and enhancing financial performance, IT that can lead to achieve the competitive advantage for manufacturing companies over others in the same industry in light in the ongoing fierce competition among industrial firms. However, the implementation of JIT allows manufacturing system a fast and efficient production of high quality products that fully meet customer needs. By producing products only when needed and with a strong quality control, manufacturing system prevents the creation of waste and thus reduces the amount of energy, raw materials and other used resources, which presents an important management tool in building ecologically sustainable business [12]. Additionally some selected articles are presented in Table 2, then discus the main concepts and roles of JIT on manufacturing industries and identify the gap and based on the concepts improvement model is proposed to basic metal industries.

Wide range of research works were conducted related to JIT concepts. This literature review analysis to summarize the concepts in the table above and it give lights on to different aspects of JIT implementation on manufacturing industries as continuous improvement tools. In addition to these, during the implementation of JIT practice on manufacturing industries we should know the following JIT Principles, such as attack fundamental problems, eliminate waste, strive for simplicity and devise systems to identify problems.

Although in order to sustain manufacturing industry, JIT believes that in order to solve fundamental problems and they need to be identified. In addition, JIT implementation will include mechanisms that will bring problems to the back. Examples of these mechanisms are statistical quality control (SQC), which monitors the manufacturing process and draws attention to any defect-producing trend, and pull kanban systems, which identify bottleneck production areas [13]. However it is possible to control the seven type of wastes (such as Rejection, Waiting, over production, Excess motion, over processing, Excess inventory and transportation) by implementing JIT on manufacturing industries $[12,14]$. Since the above literature review evident that, the benefits of JIT implementations on manufacturing industries. As a result, an integrated continuous implementation system should be considered to Ethiopian basic metal industries, so as

\begin{tabular}{|l|l|l|}
\hline Global competitiveness index & \multicolumn{2}{l|}{} \\
\hline Basic Requirement sub index & Efficiency Enhancement sub index & Innovation and sophistication sub index \\
\hline Pillar 1: Institution & Pillar 5: Higher education and training & Pillar 11: Business sophistication \\
Pillar 2: Infrastructure & Pillar 6: Goods market efficiency & Pillar 12: Innovation \\
Pillar 3: Macroeconomic environment & Pillar 7: Labor market efficiency & \\
Pillar 4: Health and primary education & Pillar 8: Financial market development & \\
& Pillar 9: technological readiness & \\
\hline Key for factor driven economy & Pillar 10: Market size & Key for factor innovation driven economy \\
\hline
\end{tabular}

Table 1: Pillars of global competitiveness. 
to enhancing sector performance. However, effective and effectiveness of JIT implementation highly effect on; strong management commitment; high quality supplies, a manageable supplier network; geographic concentration, efficient logistics and infrastructures.

The concept of total quality management (TQM): According to Karani [15], TQM is a philosophy for managing an organization in a way, which enables it to meet stakeholders' needs and expectations efficiently and effectively without compromising ethical value. Reeda [16] also elaborates as TQM is the foundation for activities, which include commitment by senior management and all employees, meeting customer requirements, reducing development cycle times, improvement of teams, employee involvement and empowerment, focus on processes and improvement plans, among others. As a result, TQM describe as a management philosophy taking on all activities through which the needs of the customer and the community, and the objectives of the organization are satisfied in the most efficient and cost effective way by maximizing the potential of all employees in a continuing drive for continuous improvement (Tables 3 and 4).
In addition to the above researchers Quality Gurus (Deming, Philip B Crosby, Joseph M Juran, Armand V Feigenbaum, Genichi Taguchi, Walter A Shewhart, Kaoru Ishikawa) also show the potentials of TQM as a continuous improvement. Since, this analysis shows that continuous improvement is a complex multidimensional concept. It reflects the favorable position of the countrywide economy, mainly in the field of global relations and cooperation of the country and, at the same time, its ability to strengthen the economy of the nations. On the other hand, the implementation of continuous improvement programs in manufacturing and services industries, that impact for the expression of national economy, scientific, technological, organizational, managerial, marketing improvement and other capabilities that are successfully insuring their competing opposite foreign goods and services at the domestic and foreign markets.

The basic quality tools in continuous improvement process: Continuous improvement involves an extensive journey, gradually building up performance, skills and capabilities within the organization to continuously find and solve problems pertaining to the company's

\begin{tabular}{|l|l|l|}
\hline Author & Findings & Journal Name \\
\hline Akbar Javadian Kootanaee et al. & $\begin{array}{l}\text { Identifies the hidden problems in the value chain and reduces the production } \\
\text { waste of the system. }\end{array}$ & $\begin{array}{l}\text { International Journal Of Economics, Business and } \\
\text { Finance }\end{array}$ \\
\hline $\begin{array}{l}\text { Zaidahmed Z Khan, and Dr. } \\
\text { Sanjay Kumar, }\end{array}$ & $\begin{array}{l}\text { Eliminate sources of manufacturing waste for attaining manufacturing } \\
\text { excellence in an industry. }\end{array}$ & $\begin{array}{l}\text { International Journal of Application or Innovation in } \\
\text { Engineering and Management (IJAIEM) }\end{array}$ \\
\hline Sandeep Phogat & $\begin{array}{l}\text { It is a systematic approach to achieve competitiveness and excellence in } \\
\text { manufacturing industries }\end{array}$ & $\begin{array}{l}\text { International Journal of Latest Research in Science } \\
\text { and Technology }\end{array}$ \\
\hline $\begin{array}{l}\text { SultanSingh and DixitGarg, } \\
\text { Sanjay Paliwal, et al. }\end{array}$ & $\begin{array}{l}\text { JIT system is mainly to reduce buffer stocks, reduce costs, and increase the } \\
\text { flexibility and to enhance the profitability. }\end{array}$ & $\begin{array}{l}\text { International Journal of management and Business } \\
\text { studies (IJMB), International Journal of Emerging } \\
\text { Trends in Engineering and Development }\end{array}$ \\
\hline Ignatio Madanhire et al. & $\begin{array}{l}\text { JIT is to improve cost effectiveness of operations, quality and to achieve world } \\
\text { class benchmarks on all facets of the engineering entity as competitiveness in } \\
\text { product delivery is getting to be mandatory for business survival. }\end{array}$ & Intional Journal of Science and Research (IJSR) \\
\hline Mahdi Salehi et al. & The implementation of JIT impact on financial Performance. & $\begin{array}{l}\text { Global Journal of Management and Business } \\
\text { Research }\end{array}$ \\
\hline
\end{tabular}

Table 2: The influence of JIT implementations for competitiveness reported in literature are.

\begin{tabular}{|l|l|}
\hline TQM Concept/principles & Main idea/Philosophy \\
\hline Continuous improvement & A philosophy of never-ending improvement \\
\hline Customer focus & Goal is to identify and meet customer needs. \\
\hline Employee empowerment & Employees are expected to seek out, identify, and Correct quality problems. \\
\hline Use of quality tools & Ongoing employee training in the use of quality tools. \\
\hline Process management & Quality should be built into the process; sources of quality problems should be identified and corrected. \\
\hline Product design & Products need to be designed to meet customer expectations. \\
\hline Managing supplier quality & Quality concepts must extend to a company's suppliers. \\
\hline
\end{tabular}

Table 3: TQM concept and definition.

\begin{tabular}{|c|c|c|}
\hline Author & Findings & Journal Name \\
\hline $\begin{array}{l}\text { Alexandra Jancikova, Karel } \\
\text { Brychta }\end{array}$ & $\begin{array}{l}\text { Analysis the core principle of TQM - continuous improvement and customer satisfaction-play vital role } \\
\text { in sustainable competitive environment. }\end{array}$ & Economics and Sociology \\
\hline Addae-Korankye & $\begin{array}{l}\text { Study investigated TQM is a source of competitive advantage in both service and manufacturing } \\
\text { sectors. }\end{array}$ & $\begin{array}{l}\text { International Journal of Asian } \\
\text { Social Science }\end{array}$ \\
\hline Kongolo and Dlamini & $\begin{array}{l}\text { Investigates the impacts of TQM implementation in Swaziland's sugar industry for increase profit } \\
\text { margins and improve quality of products, improve productivity, enhance service delivery, customer } \\
\text { satisfaction, increase product price and market share. }\end{array}$ & $\begin{array}{l}\text { International Journal of } \\
\text { Operations and Logistics } \\
\text { Management }\end{array}$ \\
\hline $\begin{array}{l}\text { Amha Mulugeta and } \\
\text { DanielKitaw }\end{array}$ & $\begin{array}{l}\text { The study presented integrated implementation of JIT under the umbrella of the broader TQM } \\
\text { initiative in synergized approach to achieve synergized results with lower resource exploitation and. } \\
\text { Also the study assessed continuous improvement efforts being implemented in Ethiopian Metal and } \\
\text { Engineering Industries. }\end{array}$ & Un-published work. \\
\hline $\begin{array}{l}\text { Yitagesu Yilma and } \\
\text { DanielKitaw }\end{array}$ & $\begin{array}{l}\text { Investigate the existing situation of the leather sector and demonstrate the importance of Continuous } \\
\text { Improvement }(\mathrm{Cl}) \text { approach as a means for competitive advantage in Ethiopian Leather and leather } \\
\text { products Industry. The study also been discovered that for companies (like Ethiopian leather and } \\
\text { leather product industries) which are suffering from low profit margin and starved economy, continuous } \\
\text { improvement could be the best choice. }\end{array}$ & Un-published work. \\
\hline
\end{tabular}

Table 4: The pervious study investigates the impacts of TQM. 
activities. However, manufacturing industries are to identify the exact quality problems, they need proper, identification tools and systems. Also they need to understand how to assess quality of products and systems by using a variety of quality control tools, how to interpret findings, and how to correct problems. There are many specific tools and techniques, which can help, improve the process performance. Cause-and-Effect Diagrams, Flowcharts, Checklists, Pareto Analysis, Histograms, Control Charts, Scatter Diagrams are the seven power full quality improvement tools, that are easy to understand, and extremely useful in identifying, analysis, investigate the problems quality practice, status and improve the performance of manufacturing industries. In the meantime, sometimes workers use only one tool at a time, but often a combination of tools is most helpful. As result, these tools need to be used quite frequently to attain continuous performance improvement of firms.

Gaps identified in from the literature review: Several researches have been conducted related to TQM and JIT practices on global competition and firm performance were mostly concerned on the developed world. For example, Kaizen, TQM and JIT manufacturing has been practiced in Toyota Production system in which still apply in implemented in developed nations [17]. But competitiveness is not only the result of having rich production factors; rather it demands the efficient and effective integration of the factors of production to get the required product or service meeting healthy and sustainable customer requirements of the world. Although in the developing world, the study of continuous improvement management practices and organizational competitiveness performance is insufficient. In addition to this the challenges in involved TQM and JIT implementation is due to infant stage of Ethiopia basic metal industry progress and their manufacturing contribution to the global competitiveness environment being almost insignificant. As result, industries in many developing countries are working on outdated technology and techniques of manufacturing systems.

Other viewpoint is the much of the earlier literature argued that competitiveness means lower costs of inputs, and that this was how countries would be competitive post-quota. However, recent literature on the post textile-manufacturing environment argues that simply focusing on lower costs in the post-quota era will not be enough to ensure competitiveness-manufacturing industries (like garment and textiles industry). According to Kitaw [18] investigates, the majority of the company's focus is on the external customer satisfaction with their product or service disregarding workers satisfaction and working environment comfort in economic lagging countries. Nevertheless today, global competitiveness in the apparel industry requires competencies that go well beyond traditional factors of relative price and low wages. Since global competitiveness should contain and fulfill multidimensional benefits to the nations includes (firm, compotator,/ sustainability, safety, product adaptability).

For example why Occupational health and safety for global competitiveness? Because health and safety comprises, technology, innovation, knowledge transfer, social, economic impacts, and environmental factors are safe.
Mankowitz [19] also show that occupational health and safety increases the health of the employees, satisfaction of the employees, and improve manufacturing systems. This result to improve firm performance and increase product quality. As well occupational health and safety highly linked with management system, quality, working environment, commitment, and satisfactions workplace. Consequently, multidimensional improvement and development has been the heart of continuous improvement and sustainable global competitiveness. Therefore, for continuous global competition and to sustain manufacturing industries, scholars should also investigate and consider this and such type points.

\section{Basic Metal Industries Competitiveness Situation}

\section{Global basic metal industry overview}

Metal industry is considered as the engine for industrial development. The progress of metal industry is the key to social and economic development. It is a catalytic in achieving import substitution, export enhancement, high degree of value addition, optimal use of agriculture, mineral and other resources and forward and backward integration with economic sectors. However, metal/steel is critical to the development of any modern economy and is considered the backbone for human civilization and development of the country. Accordingly, basic metal industries are central to build up any country's physical economic base, industrialization and development. However, steel companies have been defined as companies producing steel, from steelworks to processed steel. Hence, excluding the mining industry (raw materials) and the engineering industry (modular production) produce engineering products (Figure 2).

\section{Global steel production and consumption}

The Global steel between 2010 and 2014/15, the majority of regions have seen their shares of production decrease, including the European Union, Other Europe remained, IS, North America, South America, and Africa. Only the Middle East and Asia and Oceania had increases in their shares of global production between 2010 and 2014/15 (Table 5).

The world's largest steel producing countries are in Asia and Oceania and China. China is the world's largest steel producing country and accounted for nearly half of global production in 20122014 at $56.89 \% 33 \%$ a total of 2305.6 million metric tons steel (Figures 3 and 4).

\section{Africa basic metal industries scenario}

Ethiopian steel consumption in millions ton is given in Table 6.

\section{Global competitiveness of Ethiopian economy}

Competitiveness is a dynamic theory related to the economic policies, strategies and institutions that countries use to facilitate their trade and growth. While firms and nations, for observable reasons, need a sustainable economic policies, healthy and educated labor force to produce, their requirements also span dimensions relating to institutions, infrastructure, and business environment prevailing in a country.

\begin{tabular}{|l|l|l|l|l|}
\hline $\begin{array}{l}\text { Exploration } \\
\text { and Mining }\end{array}$ & $\begin{array}{l}\text { Smelting and } \\
\text { Slab production }\end{array}$ & $\begin{array}{l}\text { Rolling, Hardening \& } \\
\text { Finishing of metal } \\
\text { Coiling/Coating/-Formatting }\end{array}$ & $\begin{array}{l}\text { Cutting, } \\
\text { Stripping, } \\
\text { Welding, }\end{array}$ & $\begin{array}{l}\text { modular } \\
\text { production/Eng } \\
\text { ineering }\end{array}$ \\
\hline
\end{tabular}

Figure 2: Production flow of steel (Source: [19]). 


\begin{tabular}{|c|c|c|c|c|c|c|}
\hline \multirow[b]{2}{*}{ Region } & \multicolumn{3}{|c|}{ Production in Millions Ton } & \multicolumn{3}{|c|}{ Consumption in Millions Ton } \\
\hline & 2012 & 2013 & 2014 & 2012 & 2013 & 2014 \\
\hline World & 1480.9 & $1,528.4$ & $1,637.0$ & 1430 & 1475 & 1523 \\
\hline European Union & 162.9 & 160.4 & 169.2 & 140 & 135 & 138 \\
\hline Other Europe & 38.7 & 37.6 & 36.2 & 35 & 35 & 38 \\
\hline $\mathrm{CIS}$ & 82.1 & 80.4 & 105.1 & 57 & 59 & 61 \\
\hline North America & 118.6 & 116 & 119.9 & 132 & 132 & 136 \\
\hline South America & 46.1 & 45.9 & 45.2 & 47 & 49 & 51 \\
\hline Africa & 15.2 & 15.8 & 15.6 & 27 & 28 & 30 \\
\hline Middle East & 22.1 & 23.4 & 28.1 & 49 & 49 & 53 \\
\hline $\begin{array}{l}\text { Asia and } \\
\text { Oceania }\end{array}$ & 989.4 & 1043.3 & 1116.3 & 943 & 986 & 1016 \\
\hline China & 731 & 822 & 822.7 & 660 & 700 & 721 \\
\hline $\begin{array}{l}\text { World exc. } \\
\text { China }\end{array}$ & 749.9 & 706.4 & 814.3 & 770 & 775 & 803 \\
\hline
\end{tabular}

Table 5: Global steel production capacity and global consumption. Source: International Steel Administration 2016, WSA, Deloitte Report 2015 (Russia).

Global steel production Annual growth rates

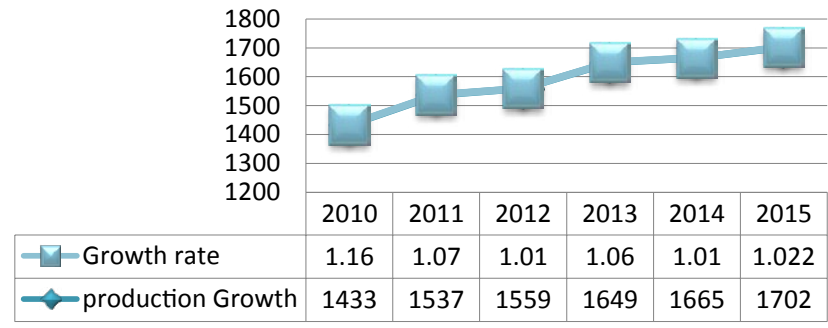

Figure 3: Global steel production Annual growth rates.

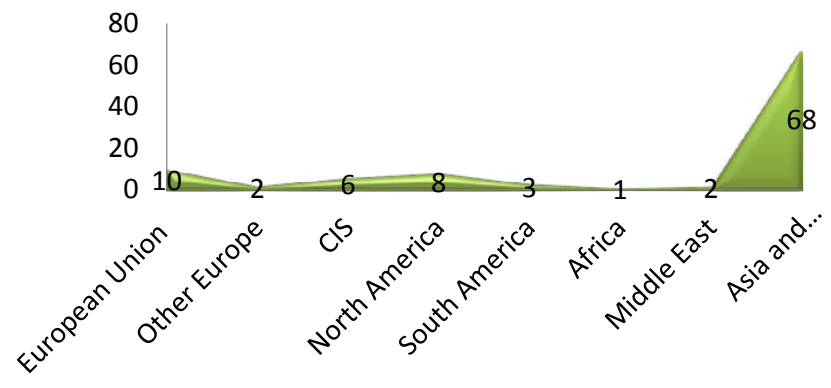

$\square$ Regional Share of Steel Production in \%

Figure 4: Regional Share of Steel Production in \%.

\begin{tabular}{|l|c|c|c|c|}
\hline & \multicolumn{3}{|c|}{ Consumption in Millions Ton } & \multirow{2}{*}{ Ave\% } \\
\hline Region & $\mathbf{2 0 1 2}$ & $\mathbf{2 0 1 3}$ & $\mathbf{2 0 1 4}$ & \\
\hline World & 1430 & 1475 & 1523 & $100 \%$ \\
\hline Africa & 27 & 28 & 30 & $2 \%$ \\
\hline Ethiopia & 1.49 & 1.9 & 2.43 & 0.14 \\
\hline
\end{tabular}

Table 6: Ethiopian steel consumption in millions Ton [Source: JICA 2010 and WSA].

However the competitiveness is found at different levels of a nations such as at Firm level, Sectors competitiveness, Regional (Area, Place, Locality, Territorial, City, Urban competitiveness), National County competitiveness), Bloc competitiveness (Regional competitiveness), and International (Global competitiveness, External competitiveness) level competitiveness. For example, a regional competitiveness can be usefully defined as the capacity and capability of regions to achieve economic growth relative to other regions at a similar overall stage of economic development, which will usually be within their own nation or continental bloc [20]. Study shows that how regional competitiveness is both allied to, and an extension of, regional growth theories, with a key factor in achieving such growth likely to be the possession of a critical stock of firms that are able to generate knowledge, entrepreneurs, and innovations in developing sectors and markets, and ultimately new jobs. Science the regional entrepreneurial, knowledge, and innovation capacity of regions are generally considered key factors underpinning the future economic development and growth trajectory of regions. Mean time regional competitiveness, therefore, is predicated on the presence of conditions that enable firms to compete in their chosen markets, and on the value these firms generate being captured by the respective region.

Subsequently, the flowing table shows the global competitiveness of report 2013-2017, is being launched at a fundamental time for the global economy. Science from global competitiveness index, the world economic forum (WEF), 2016 evaluation showed that the global competitiveness index (GCI) measurement of GCI of 2016-2017 ranked Ethiopia at 109 out of 138 countries with score point of 3.77 out of 7 score points. GCI of 2015-2016 ranked Ethiopia 109 out of 140 countries with score point of 3.74, GCI of 2014-2015 ranked Ethiopia 118 out of 144 countries with score point of 3.60 and also 2013-2014 ranked Ethiopia at 127 out of 148 countries with score point of 3.5. These indicate that according to the evidence Ethiopia listed from low income countries. Hence, the global competitiveness of Ethiopian Economy is found at the lost level. As result, companies in these factor driven economies are characterized by low competitiveness with poor technology transfer, low technological readiness and innovativeness. However, the economy needs to emphasis and intention to look at competitiveness put up an improvement of firm and sartorial level changes for growth of the company. Science the role and influence of JIT and TQM principles, implementation procedures and the relationship $\mathrm{b} / \mathrm{n}$ them are the base for basic metal manufacturing industries competitiveness. Therefore, to implement and sustain TQM and JIT as improvement tools can secure firm's competitiveness in its local and global working environment.

\section{The overview and competitiveness of Ethiopia manufacturing industry}

In Ethiopia light manufacturing industries, such as leather, textile, cement and metal are considered as strategic sub-sectors for the socio-economic development of the country (Industrial Development Strategy, 2013). This is because the nature and ability of the industries to absorb a significant labor force, contribute to export earnings and tendency to facilitate multiple linkage with the rural population in line with the country's industrial development strategy is paramount. In addition, the country endowment with rich source of raw material makes the sectors very important in competing in the international market (Figure 5).

Even though, Ethiopia is a land of huge natural resources, but we have improperly used these resources for the development. Likewise, from the table above shows, the four light manufacturing industries are poorly using these inputs due to pair of internal problems and incapacities. This statuesque is not only costing the sectors, but also makes them to be dependent on imported inputs in problems of utilizing their internal resources.

\section{Growth and competitiveness of Ethiopia basic metal industry}

Basic metal industry overview: Metal and engineering industries 
Economic Roles and Export trade performance of manufacturing Sector

\begin{tabular}{|c|c|c|c|c|}
\hline & Metal & Lather & Textile & Cement \\
\hline$\square$ GDP Contribution & $0.40 \%$ & $6 \%$ & $1.41 \%$ & 0 \\
\hline Export performance & $8 \%$ & $16.10 \%$ & $9.40 \%$ & $20 \%$ \\
\hline
\end{tabular}

Figure 5: Economic Roles and Export trade performance in each sub-secto [Source: (MoFED, 2014, Science technology information center, 2015)].

\begin{tabular}{|l|l|c|}
\hline Name of Improvement Tools Implemented & Number of Company \\
\hline Kaizen & Fully implemented & 04 \\
\cline { 2 - 3 } & Begin to implement & 19 \\
\hline \multirow{2}{*}{ QMS/ISO9001:2008 } & Fully implemented & 12 \\
\cline { 2 - 3 } & Begin to implement & 03 \\
\hline BSC/Begins to implement & & 01 \\
\hline
\end{tabular}

Table 7: Ethiopian basic metal industries implementing continuous improvement tools [Source: MIDI and NQAA].

are identified as one of the five priorities for existing industry investment to build capacity and upgrade performance in terms of utilization of capacity. The growth of basic metal and engineering industry is the key to social and economic advancement. Being a developing country the Economic growth in Ethiopia is steel intensive. According to JICA (2010) report the annual per capital steel consumption in Ethiopia is $12 \mathrm{~kg}$, which is very low as compared to even some African countries like Kenya which is $65 \mathrm{~kg}$ or African average which is $42.5 \mathrm{~kg}$ and by far low when compared to the world fastest growing economy china which is $132.2 \mathrm{~kg}$. The Ethiopian metal industry is found at very low stage of development; but is having a considerable growth. The range of products manufactured in this sector includes the production of metal from, scrap and conversion of billet, slabs etc. into primary metal products such as, tubes bars, hot rolled ribbed and plain reinforcement bars, wire rod, angles, cold rolled tubes of various profiles, cold rolled sheets, galvanized sheets and tubes. The primary metal products produced by basic metal industries are subsequently raw materials (inputs) for the downstream engineering industries. Although iron ore is believed to exist in Ethiopia, it is not mined in the country. Bars and billets are produced from iron ore, coiled wire rods, from which nails are made, and coiled sheets are imported as raw materials [21].

On the other hand, Fourtunne [22] report shows, the metal and engineering industry has underperformed both in terms of production and revenue generation. A according to report indicates that the performance of the sector are decline compared to expected targets. Out of the total planned production of 343,105 tons, only $52 \%$ was achieved by 60 industries in various areas. Translated into monetary value, these industries produced 4.85 billion Br's worth of goods. This is much less than the first quarter target of 15.17 billion Br. From the total generated revenue of 4.85 billion $\mathrm{Br}$, basic metal brought in 3.37 billion Br. However, the production of reinforcement bars generated the major share of revenue, with 105, 60 tons, worth three billion birr, produced. In terms of export performance, the industry performed well, but below targets. Frequently competitiveness pertains to the capability and performance of a firm, sub-sector or country to sell and supply goods and services in a given market, in relation to the ability and performance of other firms, sub-sectors or countries in the same market. In the era of globalization the popularity of competitiveness is clearly demonstrated by the fact that there is an increasing interest around the issue of competitiveness benchmarking at the country level as well as the policies through which governments can enhance national industrial competitiveness. Although implementation and applying of performance improvement tools like TQM, JIT, Kaizen is critical for manufacturing industries.

Continuous improvement trends in Ethiopian basic metal industries: Ethiopian basic metal industries implementing continuous improvement tools are shown in Table 7.

\section{Case company selection}

For further and a detail investigation of the basic metal sector Kaliti metal and Akaki basic factory is selected in the case studies. The case company is selected on the basis of product mix and its representativeness to medium and large basic metal product manufacturing company.

Case company selection (Kality steel industry PLC): Kality Metal Products Factory (KMPF) was established in 1968 with the objective of producing structural and furniture hollow sections, door and window frame profiles, EGA and ribbed sheets for roofing and wall cladding, galvanized corrugated iron sheet, pressed and plain sheet metal products trailer and Cargo truck bodies and other job order products. KMPF is one of the metal industries in the country that manufactures range of products. The factory was acquired by Tsehay Industry Share Company from Privatization and Public Enterprises Supervising Agency (PPESA) since July 12, 2012. It is now working with a total capital of more than Birr 700 million and with a work force of 408 workers, which is comprised of 348 male and 60 female. The fact that the factory have been in the business for more than 47 years, it has contributed significantly to the emerging industries and construction sectors through the supply of metal products. Currently the factory manufacturing the following products, Angle Irons, Flat Irons, Round Bars, U-Channels, Galvanized and Black, SECCO and LTZ door and window profiles, Trailers and Cargo truck bodies Furniture and structural hollow sections, Galvanized corrugated iron sheet, plain and press formed metal products, Garbage tankers, Dixon and Heavy duty shelves, Construction form works, Hollow sections.

For the production of these, the factory uses imported steel sheets in coils as its major input to produce standardized and job order metal products. The factory distributes its high quality and dependable products to the local market from the factory premises and through its branch sales centers located in Teklehaimanot area (Addis Ababa), Adama, Hawassa, Bahirdar and Jimma. Moreover the factory has made efforts to improve itself and its outreach by carrying out various system improvement works such as: Quality Management System (ISO 9001:2008),Kaizen, BPR,MIS Having made all those stated efforts the factory won the national first level award of excellence for demonstrating organizational excellence, outstanding practices and high commitment in managing and achieving results. However, (KMPF) has not yet reached a level to compete successfully with international companies because of limited basic metal and engineering product, and have limited marketing capabilities. As a result, the following analysis is done from the survey (Table 8).

\section{Investigation and Analysis of the Result}

\section{Competitiveness of Ethiopian economy}

Since from global competitiveness index report, the world economic forum (WEF), 2016 evaluation showed that the global competitiveness 


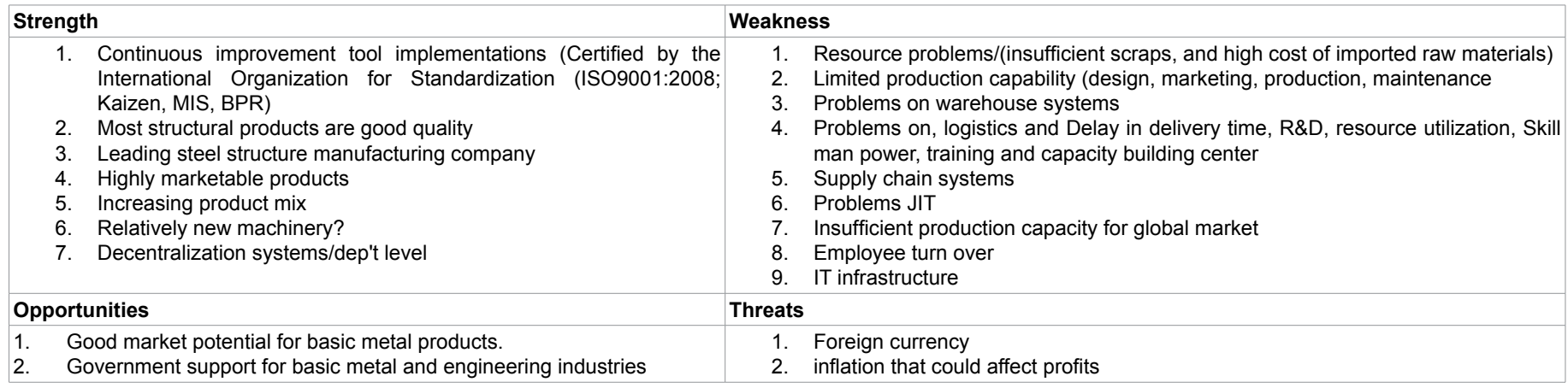

Table 8: Analysis of the strength and weakness of Kality steel industry.

\begin{tabular}{|c|c|c|c|c|c|c|c|c|c|}
\hline \multirow[t]{2}{*}{ Budget year } & \multicolumn{3}{|c|}{ Price for production/in Billion Birr } & \multicolumn{3}{|c|}{$\begin{array}{l}\text { Production capacity and usage in } \\
\text { percentile }\end{array}$} & \multirow{2}{*}{$\begin{array}{c}\text { From } 2014 \\
\text { performance } \\
\begin{array}{c}\text { Performance } \\
\text { in } \%\end{array}\end{array}$} & \multirow{2}{*}{$\begin{array}{l}\text { From } 2015 \\
\text { performance } \\
\begin{array}{l}\text { Performance } \\
\text { in } \%\end{array}\end{array}$} & \multirow{2}{*}{$\begin{array}{c}\text { From } 2010 \text { average } \\
\text { growth performance } \\
\text { Performance in } \%\end{array}$} \\
\hline & Plan & Performance & $\begin{array}{l}\text { Performance } \\
\text { in } \%\end{array}$ & Plan & Performance & $\begin{array}{l}\text { Performance } \\
\text { in } \%\end{array}$ & & & \\
\hline 2010 initial & & 6 & & - & - & - & & & \\
\hline 2011 & 20 & 6.65 & 33.3 & 75 & 53 & 70.6 & & & \\
\hline 2012 & 26 & 12.0 & 46.2 & 80 & 61 & 76 & & & \\
\hline 2013 & 33.8 & 19.02 & 56.3 & 85 & 62 & 73 & & & \\
\hline 2014 & 50.7 & 30.14 & 59.45 & 90 & 54 & 60 & 79.2 & 197.25 & \\
\hline 2015 & 101.4 & 35.84 & 35.352 & 95 & 55.3 & 58.2 & & & 55.3 \\
\hline
\end{tabular}

Table 9: production strategic plan performance (in terms of capacity and usage) [Source: MIDI and the central statistics agency]

index (GCI) measurement of GCI of 2016-2017 ranked Ethiopia at 109 out of 138 countries with score point of 3.77 out of 7 score points. GCI of 2015-2016 ranked Ethiopia 109 out of 140 countries with score point of 3.74, GCI of 2014-2015 ranked Ethiopia 118 out of 144 countries with score point of 3.60 and also 2013-2014 ranked Ethiopia at 127 out of 148 countries with score point of 3.5. These indicate that according to The World Economic Forum classified Ethiopia among low-income countries, for global index. Hence, the global competitiveness of Ethiopian Economy is found at the lost level. As a result, companies in these factor driven economies are characterized by low competitiveness with poor educational quality, poor technology transfer, low technological readiness and innovativeness. However, the economy needs to emphasis and intention to look at competitiveness put up an improvement of firm and sartorial level changes for growth of the company. Science the role and influence of JIT and TQM principles, implementation procedures and the relationship $\mathrm{b} / \mathrm{n}$ them are the base for basic metal manufacturing industries competitiveness. Therefore to implement and sustain TQM and JIT as improvement tools can secure firm's competitiveness in its local and global working environment.

\section{Basic metal industry competitiveness}

The data has been gathered from literature survey, field observation from selected basic metal industries, and different organizational reports; like Ethiopian Kaizen Institute, Ministry of Industry, Metal Industry Development Institute, Central Statistical Agency, and National Quality Accreditations Agency. Based on the survey study the trends and variables which are affecting the competitiveness of Ethiopia basic metal industries are analyze in the following ways.

Raw materials: The research data clearly shows that the Ethiopian steel industry heavily depends on raw material import from multiple countries such as Italy, Turkey, Germany, Thailand, India, Ukraine and China, rather than domestic iron making process. Survey study [5] shows that, most manufacturing firms used import raw materials for production process. This indicates that basic metal sector highly dependent on imported raw materials in their production of basic metal products. Cause for raw material supply shortage among the medium and large manufacturing industries [23]. This is due to unavailability of raw materials locally, poor quality of local raw materials, lack of sufficient local supplier and fragmental local supply chain systems are the major cause for relying on imported raw materials [4,22]. On the other hand the problems and constrains related with imported inputs were, high material cost, reliability in foreign suppliers is problematic, supply chain system problems, delay in cleaning goods through custom are the major problems that faced in Ethiopia basic metal industries. Consequently the basic metal industries production efficiency, performance, and competitiveness is poor.

Manufacturing systems: According to MIDI and the central statistics agency survey shows that, the basic metal industry sector intends to reach the 2010-2011 manufacturing year production capacity up to Billion Birr in actual its performance was 6.65 Billion Birr which is $33.3 \%$ of the intended plan. In 2011-2012 budget year the basic metal industry sub sector lay down to reach its production to be 26 Billion Birr but the actual performance of the budget year was 12 Billion Birr. In 2012-2013 and 2014-2015 budget year the production rate was intended to be 33.8 and 50.7 Billion Birr respectfully but in actual the performance was 19.02 Billion in 2012-2013 and 30.14 Billion in 2014-2015. Even if the production improvements observed on basic metal industries from year to year but numerous problems seen on basic metal industry and competitiveness till infancy. Some of the problems seen in this survey is skill man power, improper research and development center, improper production sequence, outdated technology and related problems are some of the challenges that face production capacity of basic metal industries. Because of these and other problems, basic metal firms were to produce products below their production capacity. This challenge impacts and highly reduce their competitiveness in local and global marks. As a result basic metal industries needs additional efficiency through the implementation 
of production improvement systems for local as well as global competitions.

Product quality and related issue: The survey confirmed that manufacturing firms faced problems on the availability, quality and cost of inputs. According to CSA, MIDI and JICA 2010 study shows that basic metal industry faced various problems on quality and related issue, for comparing international basic metal industries. These quality problems found due to insufficient basic metal inputs at the required quantity, quality of local raw materials, high cost of imported raw materials quality and delay on time productions are make the firms to produce products below their customer expectations. This limits their product competitiveness, as a result the firms face obstacle in terms of delivering quality products for international markets. In addition poor quality product results waste, rejects, retesting, rework and excessive overtime are also observed basic metal industries and other manufacturing sectors [24]. Since basic manufacturing industries should work effectively for organize and implementing quality management systems to fulfill quality of products and improve global competitiveness.

Technology and information systems: The study shows that, the technology currently applied are moderate in terms of affordability, suitability, accessibility, and the required level of skills. Although some of the industries have installed modern technology, most of them required to invest on a new technology. The study also shows the technology, used in manufacturing industries have an impact on global competitiveness. As a result, most basic metal industries need to invest for new technologies in the facilities for production improvement, manufacturing expansion, modernized machines, designing facilities, research and development and experimental facilities as well.

Manpower: Currently the government of Ethiopia has been emphasis and investing vast amount of investment in the construction of higher education and vocational training centers in different parts of the country to produce (train) and skilled manpower that fit for the sector. Even though this progress and development seen a country wide but our field observation and literature survey indicates that, the main challenge of manufacturing sector in most Ethiopia basic metal industry is lack of educated and trained workforce, problems in innovation, research and development, and global competitiveness $[24,25]$. In addition the sector lacks talented designers and senior manager in the area due to low wage rate, scarcity of labor, problems of facility design and inconvenient work place.

Infrastructure and energy supply: The major infrastructural related problems for basic metal industry production constraints include costs of logistics and transport, problems port facility, insufficient electricity and problems for power utilization, problems internet connection for upgrading their performance and telephone connections and poor quality of services [5]. The development of the economy of the country specially in speeding up the transition from agriculture to industry needs new technologies and modern energy supply and use, economical way of collaborating energy needs and delivery in all round energy development is mandatory in a sustainable and dependable manner in line with the country's energy policy. However, Ethiopia's current power capacity is 1,600 Megawatt (MW), which consists of hydro (86\%), diesel (13\%) and geothermal (1\%). This is not enough to meet national power demand and as a result, power failure is frequent, which is considered as the most serious obstacle for manufacturing industries [26].

On the other hand the logistics problems are mainly occurs because of the country is landlocked, it uses the port of another country and this leads to incurring additional costs for loading and unloading and for rent. But currently basic metal sector highly dependent on imported raw materials in their production of basic metal products. due to this basic metal industries invest highest amount of cost for logistics processes. This limits the firms' competitiveness in the international market as compared to other competitors.

Financial and market access: The deficiency of particular banks for industry development is also a bottle neck for the sectors development. Because for private-owned medium and large firms can't obtain enough loans from commercial banks because of different reasons like the commercial banks and the development bank have their own procedures to give loan that is not in line with the special nature of the industry, Cost of finance, lack of acceptable collateral, banks appraisal of the profitability and debt to equity ratio of the borrower. Hence, firms to large extent depend on personal sources of finance especially during initial investment. In addition cost invest for rework and defects, cost of material waste, lack of cost controlling mechanism, poor resource utilization, cost of raw materials, overhead cost and labor cost also considered as the constraints of basic metal industries. As a result of such and related constraints the production capacity and global competitiveness of the sector also limited $[27,28]$.

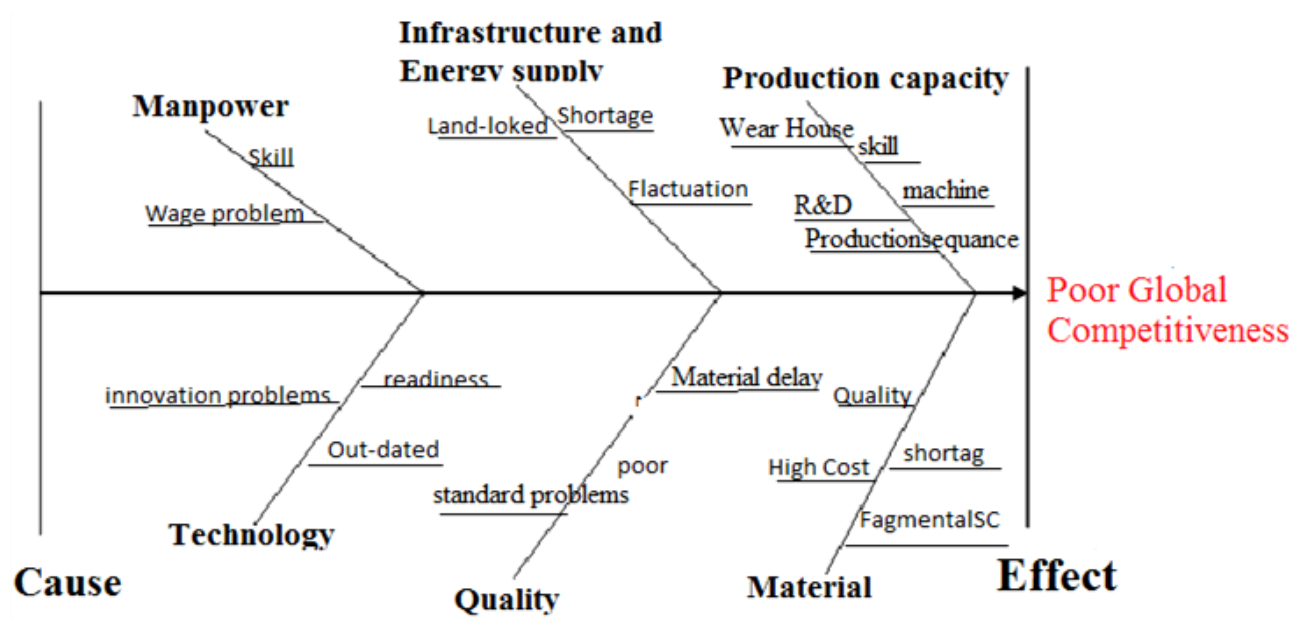

Figure 6: Constraints of Basic metal industry (Summary). 


\section{Competitiveness analysis using cause and effect diagram}

Improvements tools are widely used as "graphical problem-solving methods" and as general management tools in every process between design and delivery. These tools show the cause of problem and their effect as well to direct the improvement mechanisms for problems on manufacturing firms (Figure 6).

From the above figure we observe that the competitiveness of basic metal industries are usually evaluate from several dimensions, including the man power, technology, material and resource, infrastructure and energy supply, quality and production capacity of the firms. Due to these and other hidden factors, we investigated that the current competitive performance of the Ethiopian basic metal industry is poor. As a result basic metals sector plays a limited role in the country's economic development, GDP contribution as well as employment creation and a means of foreign substitution and foreign exchange. However, both developed and developing nation firms are now looking at securing cost, quality, technology, sustainability, knowledge, health, resource and other competitive advantages as strategies to pursue in a globally competitive environment [29-33]. As result currently in highly competitive and complex marketplace, a company follows with a more effective and efficient continuous improvement tool and systems have one of critical ingredients for improving company performances and attain global competitiveness. Therefore, improving on these critical parameters will help for enhancing the competitiveness of the sector. Although basic metal industries needs additional efficiency for global competitiveness and firm performance improvements. Since, most of the time the performance improvement is achieved by implementing appropriate improvement tools for manufacturing industries. Commonly Toyota Company use TQM, Kaizen and JIT for product and systems improvements. However to tackle the problems we intended to developed integrated TQM and JIT framework to implement in Ethiopia basic metal industries.

\section{Integrating JIT and TQM implementation strategy and model development}

Any organization needs to focus on quality of products, optimum product cost, timely delivery of products and the flexibility of their internal business process to adapt to rapid changes. Thus continuous improvement tools like Kaizen, ISO9000, TPM, TQM and JIT system is not new to the present situation of industrialization for achieving the above concepts. This technique is not limited to any particular industry but due to its large potential of benefit and it has a widespread application throughout the all industries. Many industries have adopted it and others are going to implement it for their survival in the fast competition at each stage in each area. However this survey study shows that small number of Ethiopia basic metal industry in progress to implement continuous improvement scheme to be competitive in its global marketplace. On the other hand, a number of problems discussed above tend to hold it back from achieving sustained and organization wide improvement.

Since, according to study JIT implementation is agreed to be effective for repetitive production with fairly stable demand whereas applicability of TQM is much broader as it can be implemented in large or small, repetitive or adapted production, manufacturing or survive. The study accomplished with the view that companies should implement an integrated business strategy in which JIT is viewed as a natural component of overall TQM philosophy of organizational performance improvement. As well the other researchers agree that harmonized implementation of quality improvement programs aids companies to achieve fretful improvement results [1,6]. From the literature reviews we gain that, Continuous improvement program implementation is done any of the following three methods:

1. Implemented/Adopted Continuous program as it is e.g. you can implement on of, Kaizen, TQM, JIT or other programs.

2. Sequence implementation of quality improvement programs aids companies to achieve fretful improvement results $[1,4]$. This means we can be implemented two improvement tools in the company at different time, e.g. first implement Kaizen, or JIT and then you also implemented BSC,TQM or other. Since in one manufacturing industry use two improvement tools sequentially in order.

3. Integrated implementation of two or more continuous improvement tool means integrate TQM and JIT, or TQM and Kaizen or else. Although from the literature in view of the fact that, using concepts from pervious literature, we argue that TQM and JIT have the potential tool to create competitive advantage and improve global competitions of manufacturing industries. As a result, we have to select the third option for development of our framework or model. So in most studies shows, implementation of JIT and TQM all together has been observed as common argument Vuppalapati et al. [14], Low Sui Pheng and Gao Shang. Consequently developing a conceptual framework for integrated JIT integrated TQM implementation in Ethiopia basic metal industries have significance effect on firm performance and global competitions. In JIT and TQM implementation phase, various interdependent activities need to be executed. Since from the previous literature work we take out the most important critical factors for JIT and TQM implementation to basic metal industries. Although in to consideration of this, in this study we identify these most critical factors for JIT and TQM implementation for basic, metal industries are classified in to three basic groups [34]. These are

- People evolvement issue (Supplier, Customer, Employee Commitment, Continuously monitor and control the process/ organizational, Feedback, External relations).

- Manufacturing systems (Technology, Innovation, flow, Quality team, customer expectations, performance evaluation, Flexibility).

- Resource utilization and related issue (Time, Cost, awareness and training, Waste Controlling Mechanism, Logistics). As a result, the following Models are developed for continuous improvement program (Figure 7).

Figure 7 presents the TQM and JIT integration conceptual model that has been developed as improvement model of basic metal industries. The model proposes that most of JIT and TQM practices have some aspects in common, and that they will have an impact on Sector performance. This conceptual model also suggest that there are some practices that are important for JIT, and others for TQM, but also some that are transversal for both fields, explicitly Standardization, Safety, Sustainability, customer and employee satisfaction. JIT principle Pull system/measures whether or not the plant has implemented the physical elements of a kanban/pull system. TQM principles were identified Quality Culture and Leadership (Top management vision, planning and support).

Quality culture is the shared beliefs, values, attitudes, institutions, and behavior patterns that characterize the members of a community or organization. In a healthy business culture, what is good for the company and for the customers comes together and becomes the driving force behind what everyone does. Since integrated TQM and 


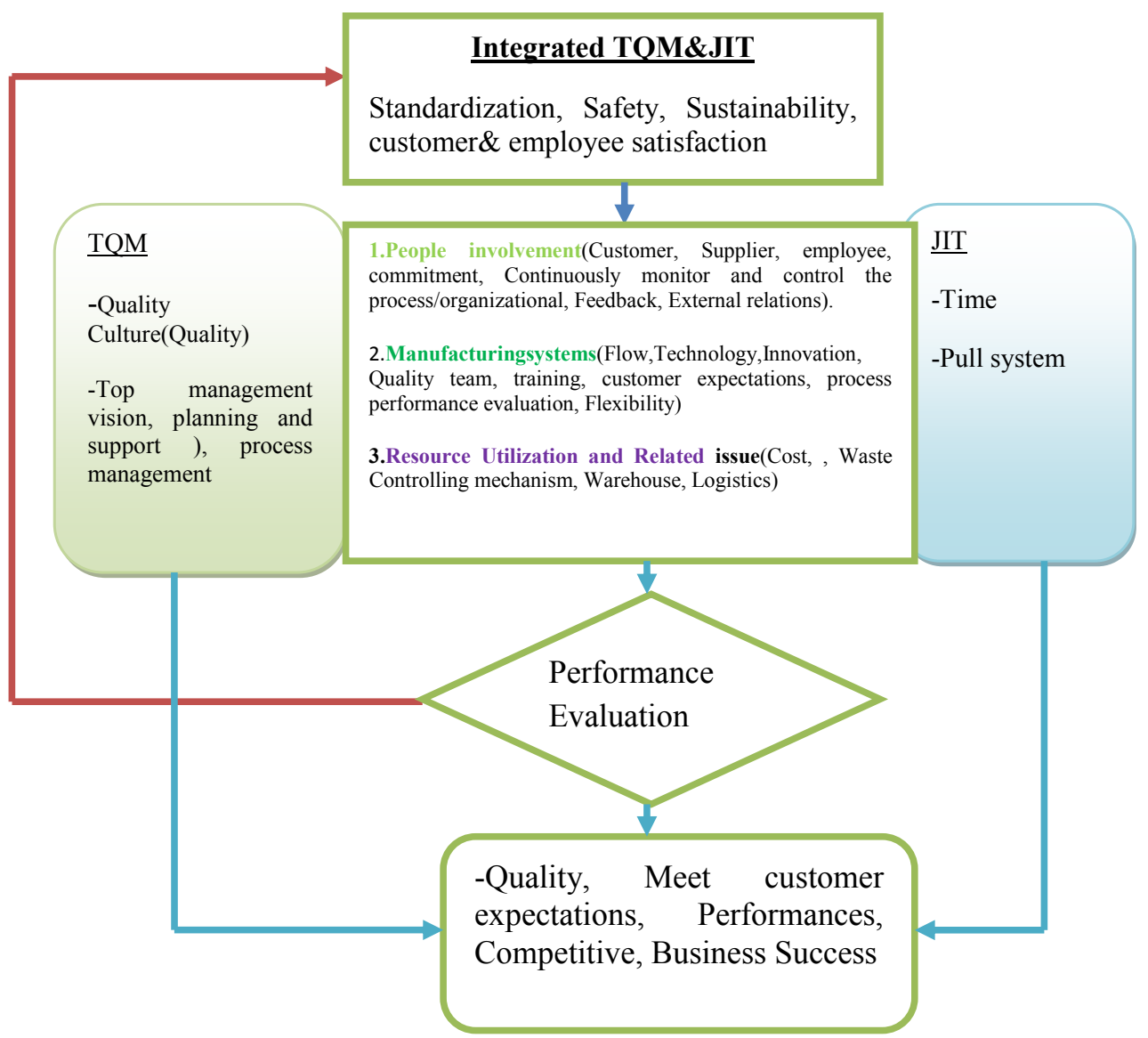

Figure 7: Conceptual model developed.

JIT implementation on basic metal manufacturing industries attempt to smooth the flow of materials, production process, information from the suppliers to and manufacturers and the customers, thereby increasing the speed of the manufacturing process, improve product quality, innovativeness, OHS and achieve sustainability and customer satisfactions. Since this program to change the manufacturing system gradually rather than drastically: In the meantime at the evaluation stage, the contribution of the improvement system should be evaluated whether the companies are improve their performance and attain their expectation or not. Depend on the industry standpoint they apply different performance measurement systems.

\section{Conclusion and Recommendations}

\section{Conclusion}

Business organizations investigate for new business paradigms that would led to competitive advantage. Just in Time (JIT), Supply chain Management (SCM), Theory of Constraints (TOC), Balanced Score Card (BSC), Total Quality Management (TQM) and Warehouse Management System (WMS) are examples of strategies that helped companies to improve production processes, reduce costs and successfully compete in a variety of business environments. However Continuous improvement program are vital for competitive advantage on firms performance improvement and resources utilizing. Competitiveness in current business environment not only focuses on local competition but also on performance of foreign companies in local market as an efficient and effective integration of resource in result of globalization. Accordingly, the aim of the study is to asses and investigates the challenges and trends of global competitiveness of basic metal industries for developing an integrated continuous improvement framework.

Since from field observation and survey data obtained MIDI, Kaizen institute (KI) and National Quality Accreditation Agency only few companies are implementing Quality management systems like, ISO 9000, Kaizen and BSC as continuous improvement program. Even if some companies implemented this continuous tools but they are not properly use. Because of improper use and limited implementation of improvements tools, poor supply chain system, manpower, raw material problems, energy fluctuation, outdated technology, manufacturing systems, financial and logistics problems are identified as the obstacles and influence the Ethiopian basic metal industry performance. Consequently, of such problems Ethiopia is missing in comparative advantage from metal sub-sectors in regional and global levels. However, to improve the deficiency seen in the sector, the integrated TQM and JIT quality improvement model has been proposed for implementation in Ethiopia basic metal industries for continuous improvement program and global competitiveness's.

\section{Recommendations}

The integration of the improvement model proposed in this study could be further studied with practical implementation and comparison with other simultaneous implementations. Basic metal manufacturing 
Citation: Dametew AW, Kitaw D, Ebinger O (2017) The Roles of TQM and JIT for Basic Metal Industries Global Competitiveness. Ind Eng Manage 6: 212. doi:10.4172/2169-0316.1000212

process always supported by research and then every industry should have research and development center.

\section{Acknowledgements}

My spirit thanks goes to almighty GOD at first because I did it he kept me alive and thereby to my supervisor Prof. Daniel Kitaw (Dr. Ing) in supporting and giving this opportunity to take action on writing this papers. The other thank goes to my dear collogues who supported me in idea sharing while we were doing together our work through similar formatting. My grateful thank goes to Ato Derjie manufacturing Department manager Ato Smuale and Ato Abomiya Senior Expert Metal Industry Development institute Ato Kashune and Mrs. Bezawite from Kality Metal product factor Quality Mentadent Team providing all necessary documents and support on Basic metal industries in Ethiopia and other Institute staffs for their collaboration, as awhile in providing any information I requested.

\section{References}

1. Kitaw Y (2014) Continuous Improvement in Global Competitiveness Arena Conceptual framework for integrating JIT in TQM implementation program. School of Mechanical and Industrial Engineering (SMIE).

2. Birhanu D (2009) Small Scale Metalworking Industries Cluster (Case Study on Towns of Oromia Special Zone). Un-published work, Addis Ababa.

3. Georgise FB, Thoben KD, Seifert M (2014) Integrating Developing Country Manufacturing Industries into Global Supply Chain. Journal of Industrial Engineering and Management 7: 174-193.

4. Dametew AW, Abebe BB, Ebinger F (2016) Study Supply Chain Integration to Basic Metal Industry. Global Journal of Researches in Engineering 16: 1-2.

5. Japan International Cooperation Agency (JICA) (2010) Basic metal and engineering industry Firm-level Study. Un-Published report, Addis Ababa Ethiopia.

6. Kitaw Y (2014) Competitiveness and beyond the production system thought in reference to Ethiopian leather and Leather products industry. School of Mechanical and Industrial Engineering (SMIE).

7. Jangwoo L, Kapsoo L, Junseok H (2015) Supplier Partnership Strategy and Global Competitiveness: A Case of Samsung Electronics. Eurasian Journal of Business and Management 3: 1-12.

8. Atkinson RD (2013) Competitiveness, Innovation and Productivity: Clearing up the Confusion. The Information Technology\& Innovation Foundation.

9. World Economic Forum (2011-2012) Global Competitiveness Report (GCR).

10. Matsui Y, Phan AC (2011) JIT Practices and Competitive Performance: Empirical Evidence from Japan. International Graduate School of Social Sciences, Yokohama National University.

11. Phogat S (2013) Introduction to JIT: A REVIEW. International Journal of Lates Research in Science and Technology 2: 97-101.

12. Milovanovic M, SISEK, Kolakovic (2011) Just in Time Concept as a Mean for Achieving Competitive Advantage in the Virtual Economy 22: 1105-1106.

13. Chaudhari SN, Patel AJ (2015) JIT Implements in manufacturing industry: A Review. International Journal of Engineering Research and General Science. 3: $1-4$

14. Vuppalapati K, Ahire SL, Gupta T (1995) JIT and TQM: a case for join implementation. MCB University Press, International Journal of Operations \& Production Management 15: 84-94.

15. Karani SR, Bichanga WO (2012) Effects of Total Quality Management implementation on business performance in service institutions: A case of Kenya Wildlife Services. International Journal of Research Studies in Management 1: 59-76.

16. Reeda R, Lemak DJ, Mero NP (2000) Total quality management and sustainable competitive advantage. Journal of Quality Management 5: 5-26.

17. Kootanaee AJ, Babu KN, Talari HF (2013) Just-in-Time Manufacturing System From Introduction to Implement. International Journal of Economics, Business and Finance 1: 07-25.

18. Kitaw D, Jilcha K (2016) A Literature Review on Global Occupational Safety and Health Practice \& Accidents Severity. International Journal for Quality Research 10: 279-310.

19. Terland T, Mankowitz J (2008) Supply Chain Management in the Swedish Steel. Un-published thesis.
20. Huggins R (2013) Regional Competitiveness: Theories and Methodologies for Empirical Analysis. The Business and Economics Research Journal 6: 155-172.

21. MIDI (2015) Basic metal and engineering industry performance report.

22. Fourtunne Addis (2016) Metal and Engineering Industry Underperforms. Addis Ababa.

23. Zavatta R, Feyissa S (2009) Baseline Survey on Competition and Markets in Ethiopia. Addis Ababa.

24. Dametew AW (2015) Problems of Solid Waste Management in Small and Medium Enterprises. International Journal of Environmental Monitoring and Analysis 3: 50-66.

25. Dametew AW (2016) Supply Chain Integration for Improving Performance on Manufacturing Industries. Global Journal of Researches in Engineering 16: 4.

26. Dametew AW (2016) Design and Analysis of Small Hydro Power for Rural Electrification. Global Journal of Researches in Engineering 16: 25-45.

27. Martin RL (2003) A Study on the Factors of Regional Competitiveness. A draft final report for The European Commission Directorate-General Regional Policy, University of Cambridge, Rotterdam.

28. Khan ZZ, Kumar S (2013) Manufacturing Excellence through JIT Approach International Journal of Application or Innovation in Engineering \& Management (IJAIEM) 2: 18-28

29. Salehi M, Alipour M, Ramazani M (2010) Impact Of JIT On Firms'Financia Performance Some Iranian Evidence. Global Journal of Management and Business Research 10: 1-9.

30. Korankye AA (2013) Total Quality Management (Tqm): A Source of Competitive Advantage. A Comparative Study of Manufacturing and Service Firms in Ghana. International Journal of Asian Social Science 3: 1293-1305.

31. Kongolo M, Dlamini DF (2014) Impact of Total Quality Management (TQM) on Service Delivery in Swaziland's Sugar Industry. International Journal of Operations and Logistics Management 3:158-169.

32. Talib F, Rahman Z, Siddiqui J, Qureshi MN (2011) Total quality managemen and service quality: an exploratory study of management practices and barriers in service industries. International Journal of Services and Operations Management 10: 94-118

33. Talib F, Rahman Z, Siddiqui J, Qureshi MN (2011) An interpretive structura modelling (ISM) approach for modelling the practices of total quality management in service sector. International Journal of Modeling in Operations Management 1: 223-250

34. Talib F (2013) An Overview of Total Quality Management: Understanding the Fundamentals in Service Organization. International Journal of Advanced Quality Management 1: 1-20. 